\title{
Towards Improving the Quality of Workspaces for a Better Human Performance in Lebanon
}

\author{
Baher I. Farahat ${ }^{1}$ and Helga O. Alaeddine ${ }^{2 *}$ \\ ${ }^{1}$ Faculty of Architecture-Design \& Built Environment, Beirut Arab University, Beirut-Lebanon \\ ${ }^{2}$ Faculty of Human Sciences-Psychology Department, Beirut Arab University, Beirut-Lebanon
}

\begin{abstract}
The quality of built environment plays an essential role in defining human behavior. Nowadays, individuals spend most of their lifetime within all types of built environments, in particular, in work environment. Employees aspire for workspaces where they can fulfill their potential and satisfy their needs. Therefore, the design of workspaces is facing major challenges and requires several transformations in order to meet the various and diversifying demands and expectations of employees. The purpose of this research is to investigate the importance of improving the quality of workspaces. This research analyses the relationship between the quality of workspaces and the performance of employees. It explores the architectural design principles and environmental conditions leading to the quality of workspaces. Moreover, it sheds light on the existing of greenery within these workspaces. A qualitative research approach is used in this research. Two national case studies are taken into consideration; each case study is analyzed based on pre-determined parameters. The sample of research is selected randomly and an interview is separately conducted. The results confirmed that both two cases meet the requirements of quality, relevant to the workspaces' design; as well as it showed that the employees had reported an increase in their performance. These results emphasize the necessity to create more national workspaces, implementing the concepts of quality and adopting international criteria of design for a better human performance.
\end{abstract}

Keywords: Quality of Workspaces; Architectural Design; Environmental Psychology; Human Performance

\section{Introduction}

The quality of built environment contributes to achieve quality of life and well-being. Nowadays, people are living and spending most of their time within built environments, in particular, work environment. The majority of these individuals form a diversifying workforce, who has a multitude of demands and expectations relevant to the nature of work and its environment. Many employees or workers perceive the workplace as unpleasant, stressful and depleting. They aspire for a new workplace where they can fulfill their potential, satisfy their needs and maintain their overall health. Workspaces have recently changed due to considerable changes related to psychosocial factors, information technology, environmental concerns and the work process. Therefore, the design of workspaces is facing major challenges and requires several transformations. Relevant literature to the study of workspaces indicated that the design and the environment have an essential influence on human behavior; also it immensely impacts the employees physically and emotionally. Studies showed that employees may waste time and energy trying to cope in poorly designed workspace, and they invest their energy in coping with adverse or uncomfortable workspace conditions rather than they invest in work. How workspace is designed and occupied affects not only how people feel, but also their work performance, commitment, health and well-being (Vischer,2008,pp.98-99). Therefore, it is essential to create new workspaces with high quality, which can lead to better outcomes. Hence, the quality of workspaces should be a major concern in order to meet the employees' expectations, fulfill their needs and promote their capabilities. This challenging task could be achieved by understanding the fundamentals of human behavior along with the exploration of the appropriate design elements. Thus, when architects and psychologists work together, they can make workspace healthy, qualified and more human. This research investigates the factors affecting the quality of workspaces which consist of architectural principles (open plans, hot desks, common spaces, functional buildings, ergonomics, and aesthetics), as well as environmental conditions (indoor air quality, thermal comfort, light and daylight, noise and acoustics, office layout, biophilia and views, look and location). Consequently this research establishes a conceptual framework to improve the quality of workspaces in Lebanon, with the aim of enhancing the performance of the employees.

Corresponding Author Email: *h.alaeddine@bau.edu.lb 


\section{Research Problem}

The quality of workspaces is becoming crucial in today's increasing global competitive world. Thus arises the need to design suitable workspaces to meet individuals' needs. It is known that incorrect patterns of design affect radically the workspaces, thus they should be addressed adequately when designing a workspace. If they are not successfully implemented within the indented design, it could have adverse impacts on the quality of workspaces and the employees as well. It is worth noting that local studies that dealt with the quality of workspaces are rare and there is a lack of information concerning this topic in Lebanon - within the limits of knowledge of the researchers.

\section{Research importance}

This research investigates the quality of workspaces. It examines the key elements of architectural and environmental design for improving the quality of workspaces which could positively affect the performance of employees. The importance of this research is formulated as following:

a. Providing advanced knowledge about the quality of workspaces.

b. Investigating the relationship between workspaces and employees' performance.

c. Examining the outcomes of greenery in workspaces.

d. Paving the way for national future researches interested in the design of workspaces.

\section{Research Aims}

a. Investigate if improving the quality of workspace enhances employees' performance.

b. Examine if the existing of greenery helps boosting employees' performance.

\section{Research Hypothesis}

a. There is a correlation between improving the quality of workspaces and the performance of the employees.

b. There is a correlation between the existing of greenery and the performance of the employees.

\section{Research Determinants}

Quality of workspaces

The workspace functions to optimize working conditions, protect and motivate employees, and enhance their well-being. The workspace should provide optimal conditions for better performance and enable employees to feel comfortable to collaborate (Abou Hamad, 2013, pp.3-4).

Architectural design

Architectural design is a concept that focuses on the aesthetical and functional aspects of the building. Architecture is not only concerned with practicality, functionality, and endurance; it is also an art form that is concerned with the aesthetic beauty of a building. While architects work to their clients' specifications and take their needs into consideration, they also use their own artistic sensibility to make each building unique (Fox, 2018). 


\section{Environmental psychology}

Environmental psychology is the study of transactions between individuals and their physical settings. In these transactions, individuals change the environment and their behavior is changed by the environment. Environmental psychology aims to improve people' relationship with their environment and making buildings more human (www.dictionary.apa/ environmental-psychology).

\section{Greenery}

Greenery refers to the natural elements, such as trees, shrubs, flowers and other vegetation. Greenery offers therapeutic benefits, and serves to provide a contemporary aesthetic element in modern workspaces. Blending gardens and plants into workspaces helps designers to create such a unique focal point (Lottrup, Grahn \& Stigsdotter, 2013, p.7).

Human performance

Human performance comprises a series of behaviors executed to accomplish specific results. It is the key factor intended to attain outcomes connected with planned objectives of the organization. Human performance depends on the interaction of motivation, knowledge, skills, attitudes, and environment (Bushiri, 2014, p.7).

\section{Design of workspaces}

One of the most important issues is the understanding and translation of the psychological and behavioral concepts into real physical world by architects (Namazian and Mehdipour, 2013, p,109). It is essential for architects to study the relationship between architecture and human behavior, in order to enhance the quality of their designs. The architectural environment should fulfill the human needs and comply with the user requirements (Abdel Kader, 2012, p.2). Architects should pay special attention to the psychological understanding of design and further exploration of human behavior in the built environment. The understanding of human behavior is crucial in designing all types of built environments; it establishes uniqueness and quality in these environments. This task could happen by understanding the concepts of environmental psychology and apply it to the architectural design (Akbari and Sattarisarbangholi, 2016, p.810).

Environmental psychology is a research field that assists architects understanding of the built environment. It investigates the effects of the physical environment on human behavior, such as environmental stressors (e.g., noise, crowding, air pollution, temperature); design variables (e.g., lighting); the design of technology (e.g., ergonomics); and ambient qualities of the physical environment, such as floor plan layouts, the size and location of buildings, and proximity to nature (www. dictionary.apa.org/environmental-psychology).

As humans around the world spend increasing amounts of time in offices in a wide variety of buildings, the effects of these environments on occupants urgently need to be understood (Vischer, 2008,p.109). The workspace has been evolving for centuries, and during the past 50 years, it has evolved much faster than ever. This is because computer and technology has exploded during the past 20 years. Given these changes, the rules of the work environment design are evolving (Kopec,2006,p.235).

Nowadays, people spend most of their time indoors, and the majority of them work in office environment. With the changes in the 21 st century nature of work, tools for work have radically changed and workspace is becoming diversifying. It is assumed that employees who are more satisfied with the physical environment are more likely to produce better work outcomes. Efficient and conducive workspaces help to reduce employee absenteeism, reduce staff turnover, and increase occupant productivity and satisfaction, thus increasing the perceived health and well-being of their occupants (Al Horr et al., 2016,p.3). The design of workspaces is often guided by general typologies (cellular office, group office, open plan office) to describe the quality of 
interactions in office structures. Numerous studies over the last decade have linking physical space with outcomes such as interaction, collaboration, innovation and performance (Elmahadi et al., 2011,pp. 381-382).

Architectural principles influencing the quality of workspaces

The role of architecture is to create places where users' needs are met and where they feel more relaxed and satisfied (Bukola et al., 2015,p.122). By understanding how people experience the built form, one can further take a more occupant-centered approach towards designing, which will lead to innovative architectural designs (Janetius, 2016,p.68).

Workspace is the physical environment which support employees' well-being and performance through office layout (open-plan versus cellular offices) and office comfort (lighting, temperature, air quality, and noise) (Carrer and Wolkoff, 2018). Nowadays, conceptualization of the work environments is shifting from the notion of workspace as a backdrop - that is, passive setting - for work, to the concept of workspace as an active support to - and tool for - getting work done. One of the results of this shift is the growing interest in how occupants behave as a function of workspace features (Vischer, 2008, p.98). Basically, the changes in the planning concepts have resulted from continuing attempts to find the best workspace formula, the design elements must be integrated successfully to create quality in work environments; they must respond to functional and aesthetic requirements as well as challenges presented by a complex workplace (Salah, 2010,p.42).

The qualified workspaces are characterized by their flexibility, collaborative features and co-working spaces; they give institutions the possibility to apply dynamic solutions to their workspaces, in such a way that employees can use the workspace whenever they want or need. The key architectural principles influencing the quality of workspaces can be summarized as following:

Open plans: The modern workspace is designed based on open plan to encourage teamwork. Employees will be able to interact while they work in a beneficial way to boost performance.

Hot desks: Open spaces are more valuable with technological advances where the employee is allowed to work almost everywhere and increase networking chances.

Common spaces: Designing casual areas for ad-hoc meetings and partnership on larger projects create a community feel to the workplace. Working together can massively improve performance.

Functional buildings: Large office buildings are now equipped with cafes, restaurants, libraries, bars, and gyms. It is assumed that happy employees are more likely to stay at the office longer.

Ergonomics: Ergonomics is the science that seeks to adapt work conditions to suit people and help them adjust to their work environment. It supports employees' well-being, and reflects a healthy mind and body overall contentment with the surroundings.

Aesthetics: Beauty is a major part of human nature; people are attached to beautiful, inspiring and attractive environments. A beautiful workspace, that takes into consideration the well-being of the employees, will lower absenteeism, increases engagement, performance and happiness. Therefore, workspaces should consider the following attributes:

How is the space accessible and by whom,

How open or enclosed is the space, 
How private is the space visual and sound wise,

How well outfitted technologically are the premises,

How much does the space encourage lingering,

How much does the space invite attention

How large is the usable space (Salah,2010,p.85; www.primeofficespace.co.uk/faq3.htm)

Environmental conditions affecting the quality of workspaces

(a). Indoor air quality

Indoor air quality (IAQ) is the degree of quality of the indoor air of a building. A workspace with good air quality has higher work performance and productivity. IAQ has received increasing attention for improving the comfort, health, and well-being of building occupants (Cincinelli and Martellini, 2017). Several diseases are caused or exacerbated by poor IAQ: allergic and asthma symptoms; pulmonary diseases; respiratory infections; cardiovascular mortality and morbidity; lung cancer; odor and sensory irritation in eyes and airways; Sick Building Syndrome (SBS) (Carrer and Wolkoff, 2018). Indoor air quality level is one of the indicators to determine the air quality of the work environment in term of the ventilation efficiency and adequacy. Studies have determined the association between indoor air quality and the prevalence of sick building syndrome among offices workers (Rosli and Jalaluldin, 2012, p.99).

\section{(b). Thermal Comfort}

Thermal comfort is described as a state of mind which expresses satisfaction with the thermal environment. Thermal comfort in a workspace is measured by analyzing the number of discomfort complaints, and it is influenced by six factors: air temperature, air velocity, relative humidity, mean radiant temperature, clothing insulation and metabolic rate. Achieving thermal comfort requires energy consumption by the heating and ventilation systems in a building. It has attracted many researchers focusing on sustainability in the built environment. Studies indicate that dissatisfaction with thermal comfort leads to productivity loss, and decrease in the performance of occupants (Al Horr et al., 2016, pp.374-375).

\section{(c).Lighting and Daylighting}

Light is a cognitive map able to guide and direct the individual in the exploration and discovery of the surrounding environment (Tomassoni et al., 2015). Humans need light as it is a regulator of performance. Employees spend most of their time indoors thus office tasks are dependent on indoor lighting or any available daylighting. Daylight is the best source of light for human visual comfort. It provides a sense of cheeriness and brightness, and has a positive impact on people. Building occupants prefer natural light/sunlight over artificial light; this preference is due to physical, physiological and psychological reasons. These reasons affect the visual and circadian systems; as well they influence melatonin, a hormone responsible for regulating the body's internal clock and light levels (Al Horr et al., 2016, p.375).

(d).Noise and Acoustics

The World Health Organization (WHO) describes any unwanted sound as noise. Noise and acoustics have high relevance in building design. Bad acoustic and noise can lead to dissatisfaction with the work environment and affect workers' performance. Noise is identified as an ambient stressor, it affects the physiological and psychological health of the individual, it can impact the likelihood of developing cardiovascular and sleep 
disorders, and also it causes auditory discomfort, annoyance, irritability, and changes in behavior (Abou Hamad, 2013, p.8).

Consequences of workplace noise, such as hypertension, hearing impairment, disturbance of well-being, and psychiatric disorders have been described. Research has found that employees working in spaces in which noise distractions are reduced, performed significantly better than peers working in environments where they could be more easily interrupted by noise (O’Neil, 2008). Office workers report " the ability to concentrate without noise and other distractions"' to be one of the most important aspects of the work environment (Kamarulzaman et al., 2011, p.265-266).

(e).Office Layout

Office layout design is one of the leading indoor qualities that influence the performance of users. Design, proximity and privacy influence employees' work patterns, behavior and performance. The suitability of an office layout affects the employees' performance. Office design and layout is highly affected by external factors, and it is influenced by organizational and national cultures (Al Horr et al., 2016,p.377).

A fundamental aspect of the contemporary work environment that contributes to positive employee' behavior is the layout of office. The contemporary open-plan design is characterized by an absence of floor to ceiling walls and internal boundaries, as illustrated by cubicles or partitioned workspaces (Kamarulzaman et al., 2011, pp.263-266).

\section{(f).Biophilia and Views}

Biophilia describes the innate relationship between humans and nature, and the need to be continually connected to nature. Humans are highly responsive to nature's forms, processes and patterns. Bringing natural environment inside workspaces has a positive effect on the employees' satisfaction. Views of nature and plants from windows have been reported to help reducing anxiety, stress, elevating the positive mood, and increasing the productivity and well-being of employees (Al Horr et al., 2016, p.378). Visual connection with nature is an important aspect of biophilia as it deals with elements of visual comfort and relaxation. It is also one of the most evident ones when it comes to identifying design parameters; many studies showed that views of nature regulate and maximize functioning of occupants and enhance their creativity (Asim and Shree, 2019, pp.20-21).

\section{(g).Look and feel}

The look and feel of a work environment can have an impact on well-being. Good aesthetics act as a pleasing feature in any physical environment. Shapes, textures and colors of the environment affect office occupants. Studies indicate that color schemes and the aesthetics of an indoor environment affect human performance and productivity (Al Horr et al., 2016, p.378). The color scheme chosen for a workspace must be made with proper consideration to produce better quality of work. Good workspace color can have a positive influence on work outcomes such as visual working capacity, performance, productivity and creativity (Savavibool et al., 2018, pp.150-156). The texture of an object is as important as its color. Textures are an important part of our memory and remain in memory like shapes and colors. The combined effect of color, texture and shapes of interior design in a work environment lead to the well-being in a workplace. Spatial shapes also play a significant role in defining the quality of a workplace (World Green Building Council, 2014).

(h).Location and amenities

The location of the workplace and its amenities are highly significant in defining the level of its quality. Workspaces located in the proximity of public infrastructure have higher employee' satisfaction; Workspaces located near to good quality public transit services, cycle tracks and offer good walkability tend to provide 
easier and convenient access to its employees. Research suggests that employees' walkability reduces the risk of obesity, keeps them healthier and hence more productive. In Addition, amenities' provision can influence the productivity of employees, increase their satisfaction and motivation (Al Horr et al., 2016, p.378). It is recommended to have four types of amenities near a work environment: Health care/ clinic - Recreational spaces/sports facilities - Entertainment options - Childcare facilities (World Green Building Council, 2014).

Greenery

In today's contemporary built environments, people are increasingly isolated from the beneficial experience of natural settings that they find particularly appealing and aesthetically pleasing. So, by mimicking these natural environments within the workplace, designers can create workspaces that are imbued with positive emotional experiences (Robertson, 2015,p.10). Research shows that green spaces help to reduce stress, enhance psychological recovery, and have a beneficial effect on health. Many studies from Europe, North America and Asia report that natural environments evoke positive moods (tranquility and energy), decrease negative moods (anger and sadness), and improve concentration, creativity and performance (Tyrväinen et al., 2014, pp.1-2). Studies indicate that workers are reported to be less tired when they have access to plants or views, and prefer work environments with living plants and window views (Kamarulzaman et al., 2011,p.266). More than aesthetically pleasing, greened indoor workspaces are calming spaces; they are designed to reduce stress, enhance overall wellness and boost productivity. Incorporating greenery like plants into workspaces is a good way to keep the employees happy and healthy. Plants provide health benefits as they are natural air purifiers. Bringing plants into office spaces can reduce toxins, essentially becoming a great air filtration source. As the NASA Clean Air Study points out, plants can trap air pollutants in its tissue providing cleaner air for employees (Pope, 2018).

Environmental psychology research shows that being connected to nature is an adaptive human function that allows for, and assists with, psychological restoration. Views of natural scenes were linked to the greatest levels of well-being among office workers. Workspaces that incorporate nature provide more tranquil settings that allow for more effortless attention, less mentally draining and may restore mental capacity and cognitive abilities. By providing nature contact within the workspace, we can ensure consistent levels of job performance (Robertson, 2015, pp.19-20). It is important for designers to keep in mind that adding plants can be an attractive, practical and cost-effective way to improve air circulation. In fact, a recent report by the University of Twente, VU Amsterdam and CBRE found that implementing greenery into the workplace design has substantial benefits on energizing the workers, boosting their happiness, and improving of healthiness' feelings and competition (Pope, 2018). Therefore, greenery is described as productive, motivating and good for the working atmosphere. The fact that plants transmit a multitude of positive effects to interior spaces has been confirmed by numerous studies (Schaberl, 2019). Studies have strengthened that greenery in design helps improving the overall health of the occupants and affect positively their levels of satisfaction, quality of performance and productivity (Asim and Shree, 2019,p.18).

Human performance

Human performance is defined as a group of behaviors which express how the employee performs his job with high quality of performance, good implementation, technical experience of the job, communicational interaction with other staff members, and the commitment of the administrational rules which organize the job and upgrade it to better response carefully" (Salah, 2010, p.68). Organizations need highly performing individuals in order to meet their goals and to achieve competitive advantages. Performance is also important for the individual: accomplishing tasks and performing at a high level can be a source of satisfaction, with feelings of mastery and pride. Low performance might be experienced as dissatisfying or even as a personal failure. Moreover, performance is a major prerequisite for future career development and success in the labor market (Sonnentag and Frese, 2005, p.4). Many studies have sought to make direct links between the environmental design of workspaces and employees' performance. Individual performance is affected by environmental conditions such 
as lighting and visual conditions, temperature and humidity, furniture ergonomics, spatial layout and acoustics. These elements have a powerful effect not only on the satisfaction of employees but also on the performance of teams (Vischer, 2008, pp.101-103). A proper workplace environment helps in reducing the number of absenteeism and thus can increase the employees' performance. There are several factors that being described towards the success of the employees' performance, such as physical work environment, equipment, meaningful work, performance expectation, feedback on performance, reward for good or bad system, for standard operating procedures, knowledge, skills and attitudes (Bushiri, 2014, p.9).

\section{Methodology}

\section{Research Methods}

A qualitative research approach is used in this research. Two national case studies are taken into consideration; each case study is analyzed separately based on pre-determined parameters. The sample of this research is selected randomly and it is divided into two different samples: the first sample consists of 35 users $(\mathrm{N}=35)$, the second sample consists of 25 users $(\mathrm{N}=25)$. An interview is separately conducted with the users to self-report their performance. The analysis of the two case studies parameters, and the interviews' content, is followed by an evaluation, based on informational data, aiming to prove whether the research' hypotheses are true or not.

The Criteria of selection are as follows:

- Same function

- $\quad$ Same target users

- Treatment of the spaces

- Performance of the employees / users

The Parameters of analysis are as follows:

- Why it works

- Why It is meaningful

- Why it is valuable

- Architectural concerns 


\section{Case studies analysis}

\section{Case one: Antwork, Beirut -Lebanon}

Table 1: Antwork ID card

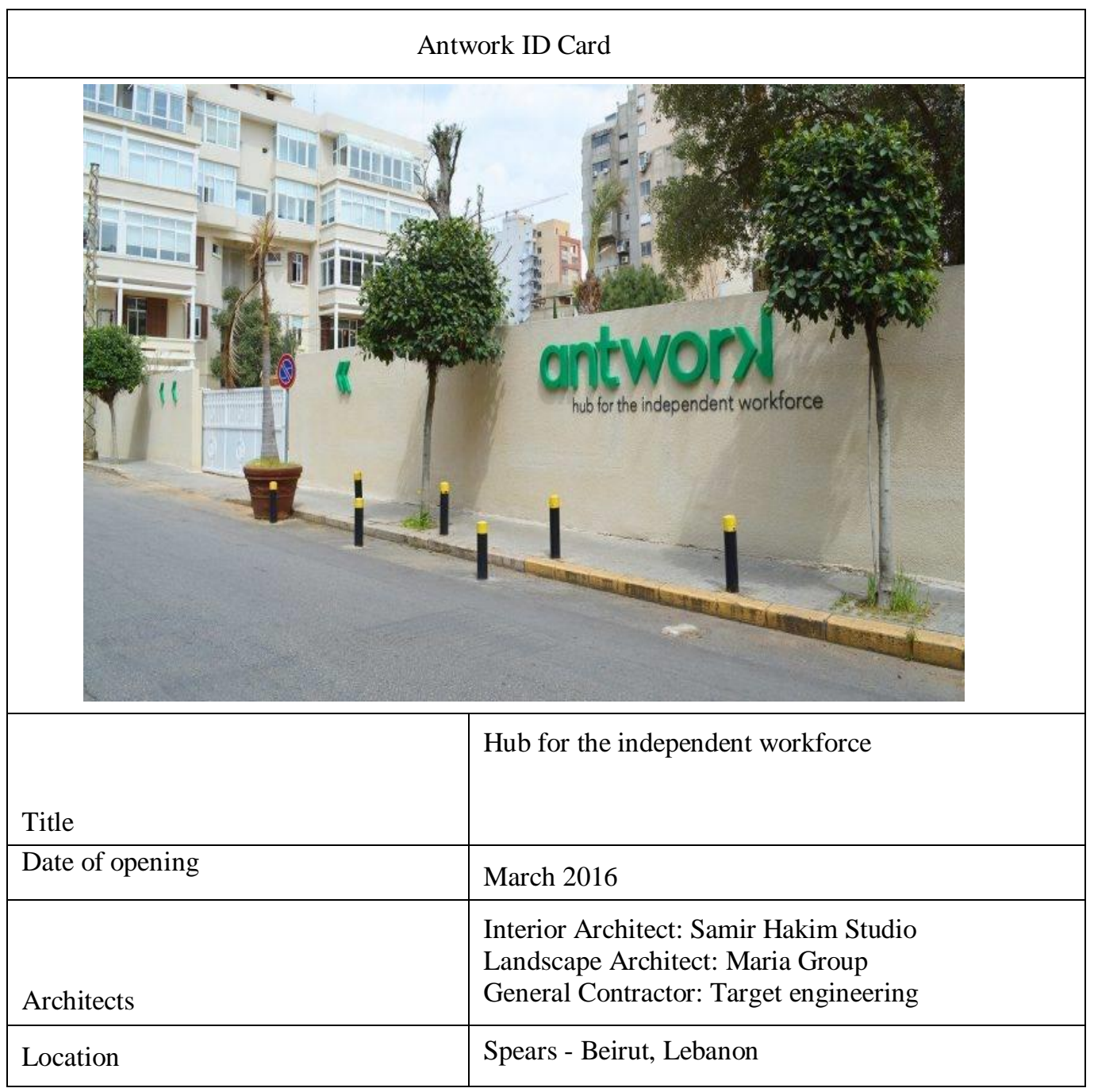

Voted as the best co-working space in Lebanon in 2018, Antwork has been welcoming coworkers from all backgrounds into an innovative space, a collaborative environment, and highly empowered community. Antwork is a collaborative space that is designed to welcome diverse communities of entrepreneurs, solopreneurs, freelancers, startups, and techies. With intricacy in design and innovation in technology, users will be able to split their space into micro-leasing opportunities; from leasing a desk to the abundance of entrepreneurs, to leasing full-fledged offices to the rising start-ups, and enterprises with changing spatial needs. Powering up their space enables users to connect to international and local communities of coworkers, as well as host their own local and international networking events (www.antwork.com). 


\section{III-2.1.a. Parameters of Analysis}

- Why it works:

Antwork is a leading launch pad for growth in emerging entrepreneurial ecosystems, offering the open spaces startups cannot afford on their own. It is constantly evolving and enhancing the set-up of the spaces to meet the needs of its users. Located in the heart of Beirut city, Antwork is accessible and can be shared by individuals, several companies and organizations, see Fig. 1

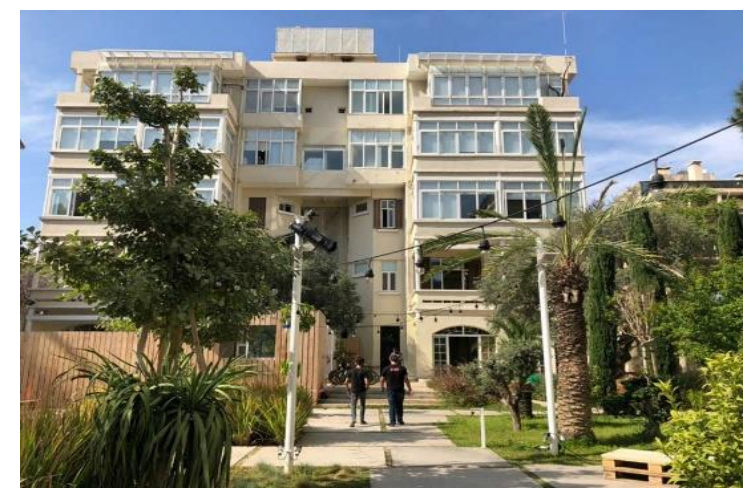

Figure 1: Antwork Block A (www.antwork.com)

- Why it is meaningful:

Antwork meets the needs of the new generation that seeks spaces that are flexible and comfortable instead traditional offices. Antwork cares about the well-being of the users, how they feel and how they interact with each other. It provides users with a wide range of plans and on-demand amenities to cater to all users' working needs, with collaborative and connected spaces, see Fig. 2

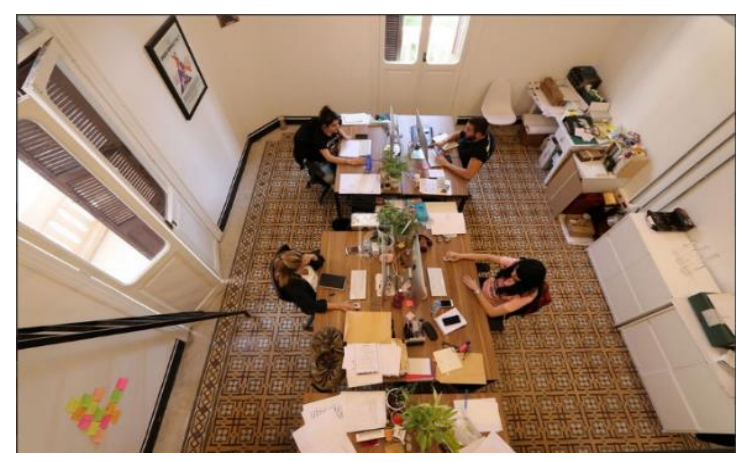

Figure 2: Antwork Flexible Workspace (www.antwork.com)

- Why it is valuable:

Antwork is characterized by its space consultation: with its workspace science and study of workspace behavior, users can adopt the golden ratio between private, semi-private, and shared agile spaces. Making the most out of every space and optimizing the revenue generation. Each space is treated differently, yet users' approach is budget conscious and eco-friendly, see Fig. 3 \& 4 


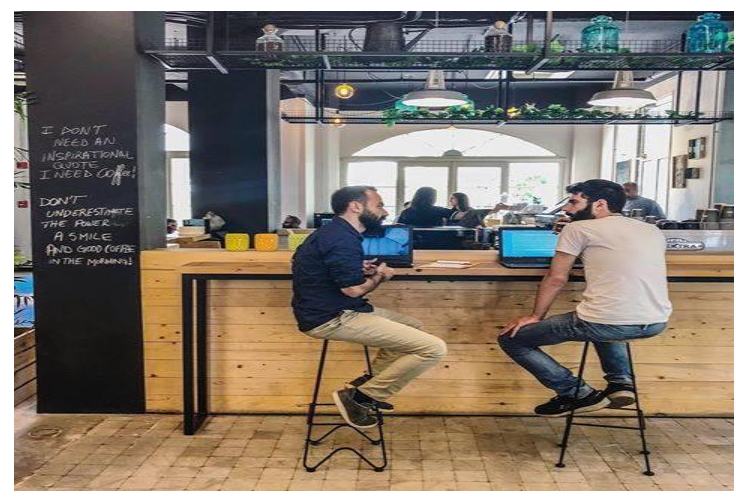

Figure 3: Antwork Coffee bar (www.antwork.com)

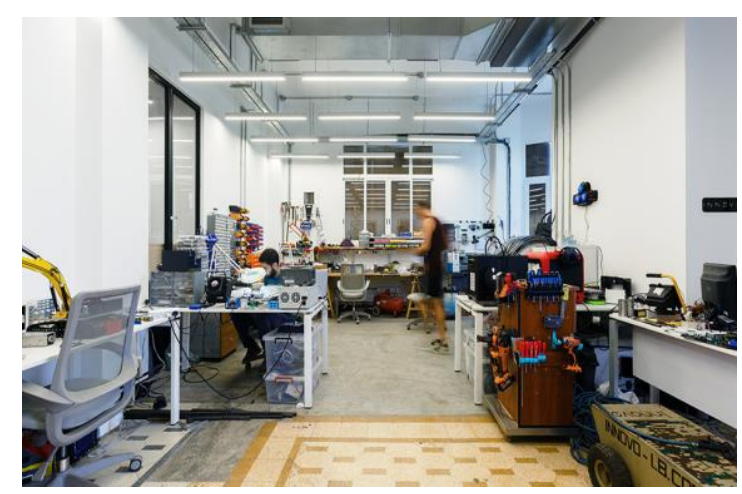

Figure 4: Antwork Specialized Studios (www.antwork.com)

\section{- Architectural concerns:}

Antwork design depend on the flexibility of design where portions are dominant to create different zones. It achieves a highly productive workspace by providing more than one space. It contains open and common spaces where people can share ideas together, besides hot desks and private workspaces to let the employee have his personal spot, while providing the right amount of privacy; in addition to the events spaces, the accessible rooftops and balcony, see Fig. 5, 6 \& 7
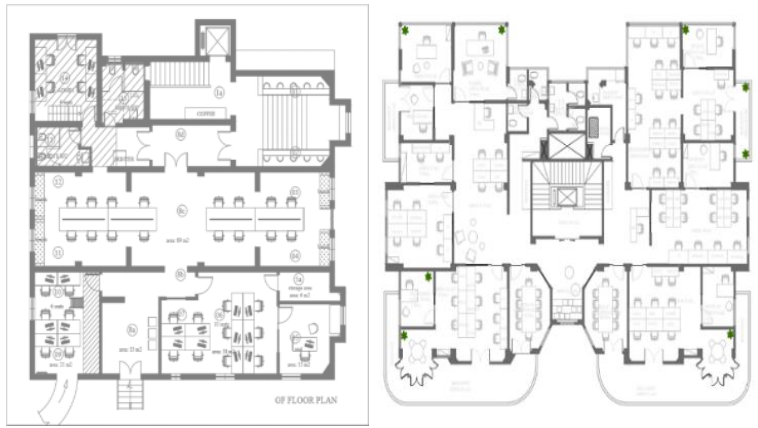

Figure 5: Antwork Plans (Authors) 


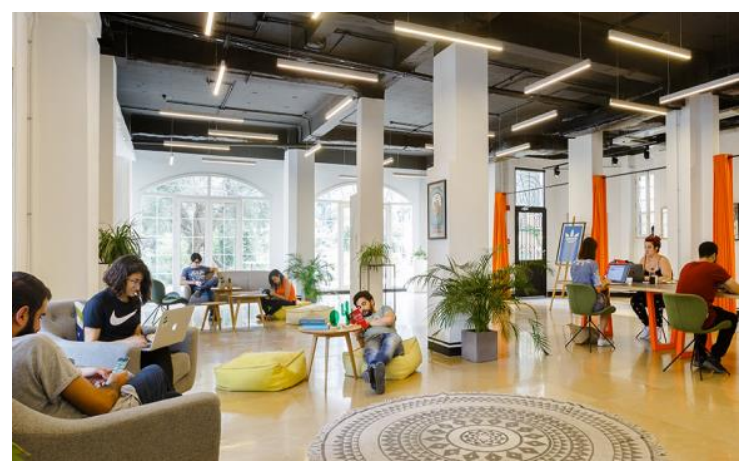

Figure 6: Antwork Hot Desks (www.antwork.com)

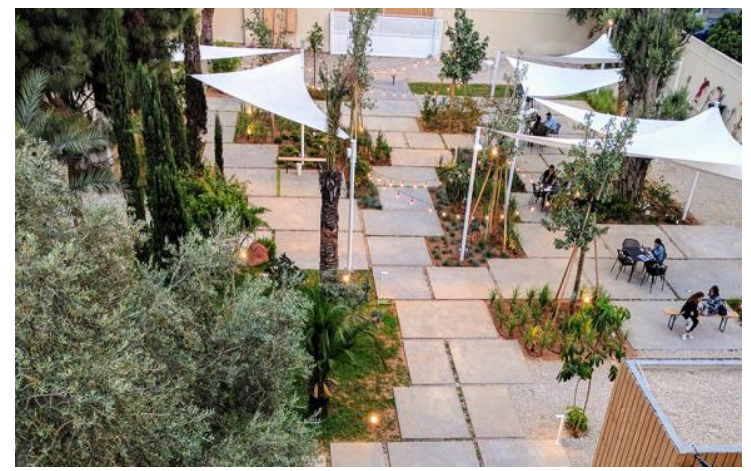

Figure 7: Antwork Events Spaces (www.antwork.com)

\section{Evaluation}

Based on direct observations and the interviews conducted with a sample of users $(\mathrm{N}=35)$, we seek to examine if Antwork meets the criteria of quality relevant to workspaces. Firstly, it implements almost all the architectural design principles presented in our research: it is modern and characterized with open spaces that consist of hot desks suitable for all kinds of workers; the private workspaces are fully furnished and equipped, accessible 24/7, and are designed to create a conducive environment for impactful work; the meetings rooms are inviting and useful; in addition, Antwork contains a restaurant, a coffee bar and a library which make it a functional building; it introduced a set of new, unconventional, and meticulously designed event spaces; its surrounding is green, the balconies and rooftops offer natural views; flexible ergonomics are taken into consideration with basic infrastructure, electro-mechanical systems, refurbishment, fixtures \& furniture; the sense of aesthetics is simple to make users feel at ease. Secondly, the environmental conditions presented in our research are mostly fulfilled: the indoor air quality is good; thermal comfort is achieved by traditional heating and ventilation systems; the level of lighting is adequate and there is an appropriate access to daylight; there is no noise and the acoustics are good; the office layout is characterized by open plans and collaborative spaces, besides private spaces; it feels quiet with calm colors and simple textures; it is located in a significant district and it is having many nearby facilities; the greenery is richly implemented indoors and outdoors. On the other hand, concerning the performance, the interviewed sample of users $(\mathrm{N}=35)$ reported that Antwork is a pleasant and functional workspace: it supports their work plans, meets their expectations and boosts their productivity. They confirmed that their performance is highly affected by this work environment. In addition they have reported feelings of satisfaction. Based on what we had stated above, Antwork is considered a qualified workspace that fulfill most of the quality requirements mentioned in the literature review. 


\section{Case two: The Olive Grove, Beirut-Lebanon}

Table 2: The Olive Grove ID card

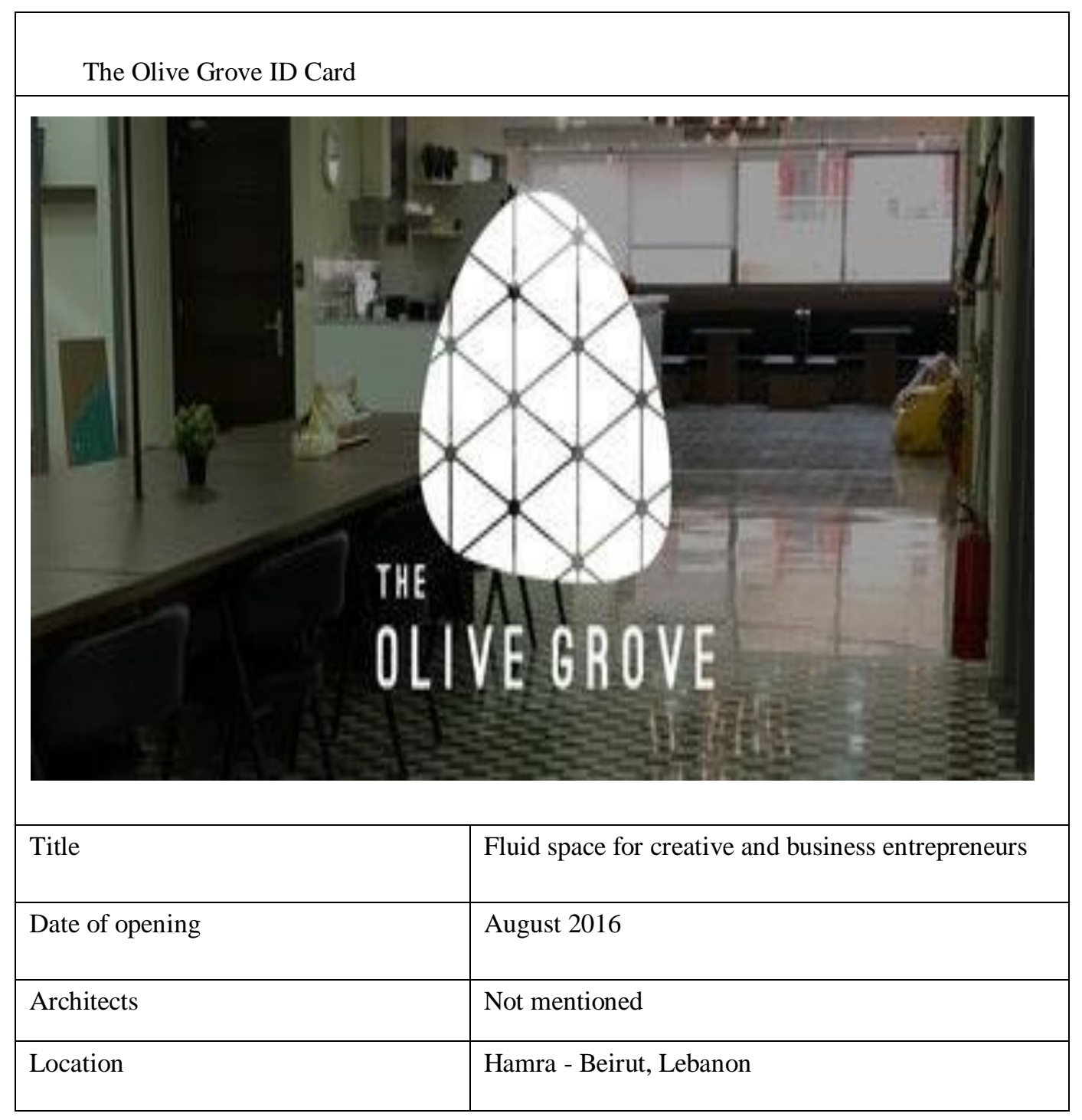

The Olive Grove encourages entrepreneurship and innovation in the Middle East, which holds great potential for growth, development and stability in the region. It comes alongside young Lebanese entrepreneurs who want to shape their communities and country by defying the status quo, overcoming obstacles and striving toward a more innovative future. The Olive Grove aims to make entrepreneurship \& mentorship accessible to everyone, and to partners in the Beirut startup ecosystem to foster regional growth and innovation. It bridges the gap between what Lebanon needs and what our local talent has to offer by providing a fluid space for creative and business entrepreneurs, with a focus on personal and corporate mentoring, in aim to address the national brain drain (www.togbeirut.com). 


\section{a. Parameters of Analysis}

- Why it works:

The Olive Grove is a co-working space that fuels creativity, productivity and sense of community. It has ambitious future plans of the spaces to meet the needs of its users. The Olive Grove, located in Beirut city, is accessible to all types of users and equipped for many work purposes, see Fig. 8

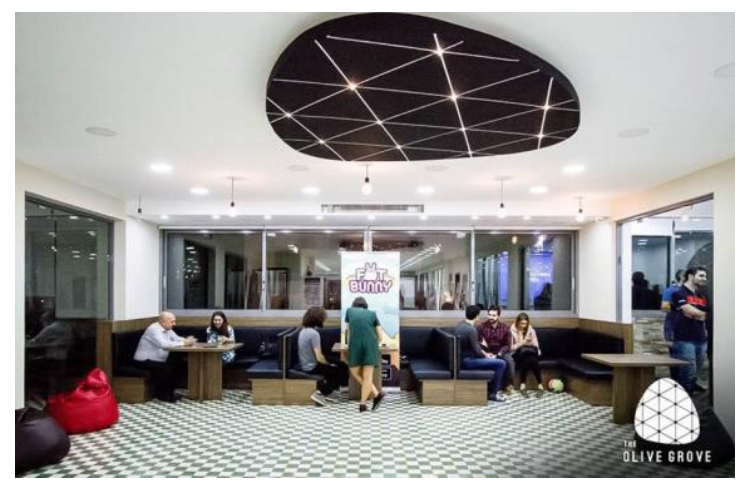

Figure 8: The Olive Grove Flexible Workspaces(www.togbeirut.com)

- Why it is meaningful:

The Olive Grove provides regular seminars from entrepreneurs and artists, a curriculum to walk members through steps to start a business, and personal mentorship, see Fig. 9

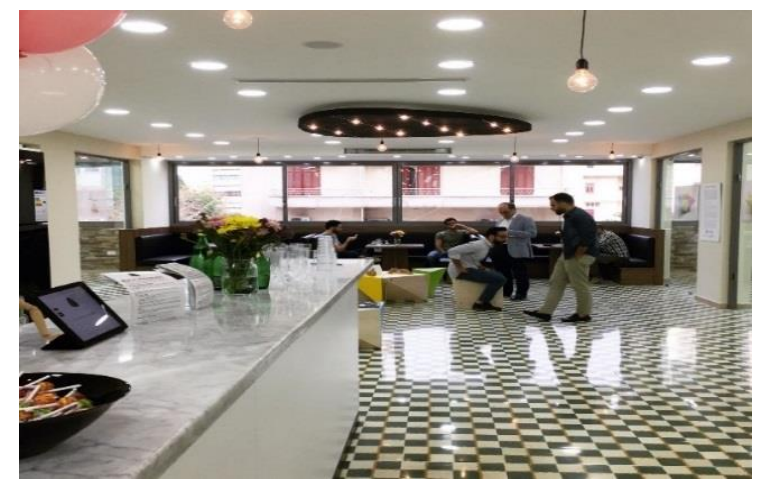

Figure 9: The Olive Grove Co-working spaces ( $\underline{\text { www.togbeirut.com })}$

- Why it is valuable:

The Olive Grove is an example for companies which look for modern and innovative workspaces. It seeks to find work spaces that are flexible, interactive, and productive at the same time, see Fig. $10 \& 11$ 


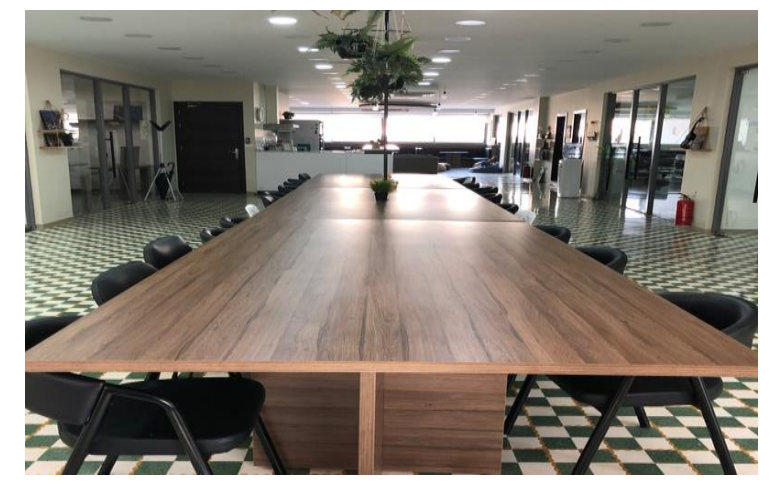

Figure 10: The Olive Grove Large Shared Workspaces(www.togbeirut.com)

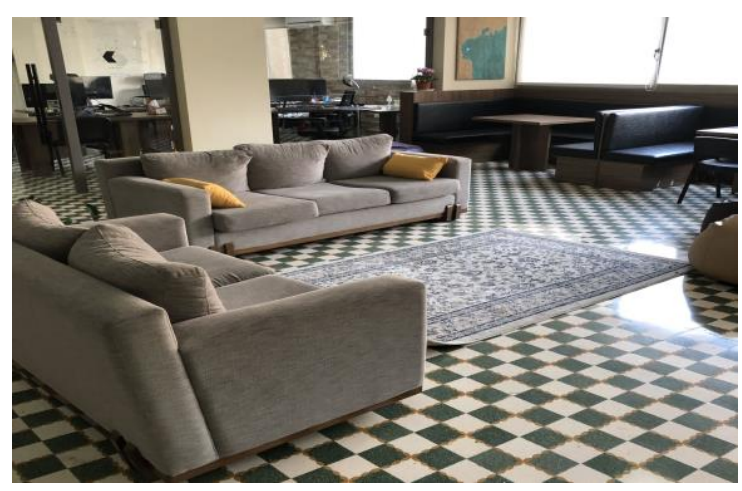

Figure 11: The Olive Grove Common Spaces (www.togbeirut.com)

\section{- Architectural Concerns:}

The Olive Grove spaces are designed to foster a flexible and collaborative space. The objective is to give all users the freedom to take a break, have a chat, move around, and relax while remaining within their workplace mindset, and ultimately creating a work/life balance that compliments productivity, rather than hinder individual and/or group goals. Hot desks are suitable for freelancers, artists, creative employees or entrepreneurs; small and large offices are accessible for everyone; shared spaces are designed smoothly for all purposes, see Fig. $12 \& 13$

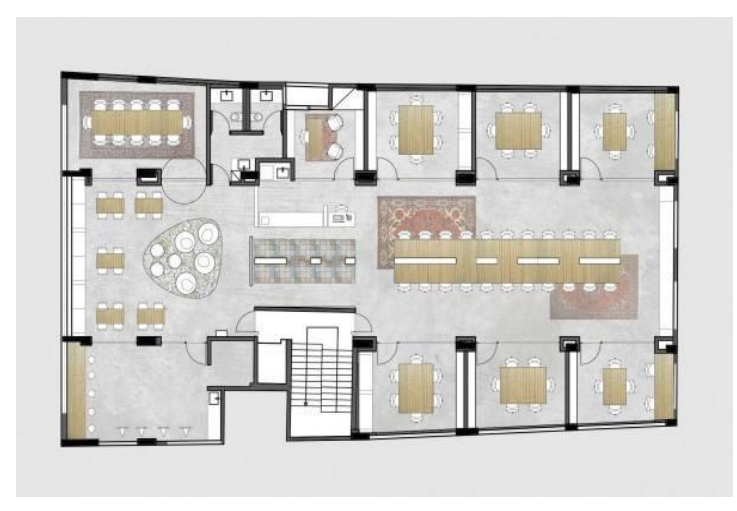

Figure 12: The Olive Grove Plans (www.slideshare.net/BorisZupani/workspace-the olive grove) 


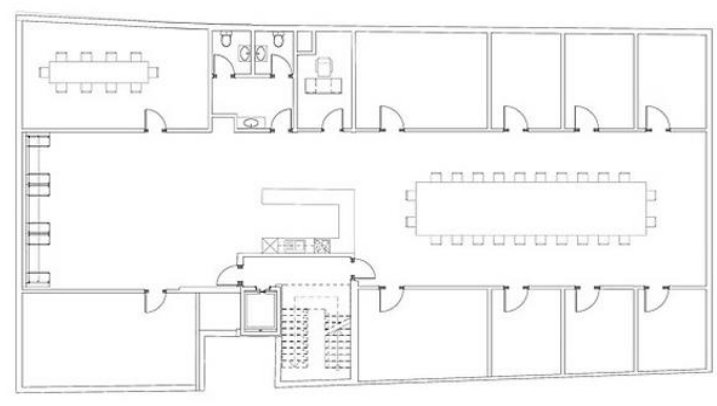

Figure 13: The Olive Grove Plans

(www.slideshare.net/BorisZupani/workspace-the olive grove)

\section{b. Evaluation}

Based on direct observations of the researchers and the interviews conducted with a sample of users $(\mathrm{N}=25)$, we seek to examine if The Olive Grove meets the criteria of quality relevant to workspaces. Firstly, The Olive Grove implements many of the architectural design principles presented in our research: accessible open plans to all users; equipped hot desks; private offices for small teams; large offices and common spaces suitable to teamwork; the functionality of its building is good; plants are bringing indoors; ergonomics are adjusted to users' needs; aesthetics aspects are prevalent. On the other hand, the environmental conditions are mostly fulfilled: indoor air quality is good; thermal comfort is convenient; the level of lighting is adequate and the daylight is provided; it feels calm with warm colors and simple textures; the level of noise is controlled; the office layout is characterized by flexible and interactive spaces; its location is significant and surrounded with many amenities; Concerning the performance, (22) users of the interviewed sample $(\mathrm{N}=25)$ reported that The Olive Grove is a comfortable workspace: it helps them to work at ease, satisfy their demands and boosts their energy. Based on what we examined above, The Olive Grove is considered as qualified workspace that fulfill many design requirements mentioned in the literature review.

\section{Discussion}

The researchers find the following:

1- Hypothesis $1(\mathrm{H} 1)$ is true. There is correlation between improving the quality of workspaces and the performance of the employees.

This research investigates the importance of improving the quality of workspaces, which could be achieved through specific architectural design principles and environmental conditions. The results confirm the correlation between improving the quality of workspaces and the performance of the employees/users. The results assume that implementing the criteria of quality while designing workspaces have positive impacts on the perception of these spaces by the interviewed employees/users and respectively it enhances their performance. This research confirms what most of previous studies have shown about the correlation between the quality of workspaces and the performance of the employees.

2- Hypothesis $2(\mathrm{H} 2)$ is true. There is a correlation between the existing of greenery and the performance of employees.

This research assumes the importance of green design, and confirms the impacts of having greenery within workspaces on the performance of employees. The results show that the existing of greenery is recommended by the interviewed employees/users, who reported that it is an essential aspect of the quality of their workspace. In addition, they pointed out that it boosts their energy, sense of comfort and 
performance. A huge body of previous studies has indicated the impacts of greenery in workspaces on the behavior and health of employees, thus this research confirms these findings.

This research concludes that it is essential to examine the relevant architectural principles and environmental conditions to create a workspace with high quality, in order to provide better outcomes for individuals, institutions and community.

\section{Conclusion}

It is fundamental that workspaces reflect the community and represent a suitable environment for employees, taking into consideration the individuals differences, the fulfillment of their needs and expectations, assuring them the sense of belonging, and enhancing their performance. A qualified workspace isn't only a physical environment or some random built environment; it is a vital space that architects and psychologists should invest their in depth-knowledge to make it worthy for human development and individual flourishing.

It is needful to create workspaces where people can flourish within, and that was the aim of this research. However, it has some limitations:

1) The sample consisted of 60 respondents, interviewed to self-report the quality of their workspace and performance. The researchers had randomly selected this sample, and aspired to collect a larger sample but the time and work schedule of respondents make it difficult.

2) Two national workspaces were selected, located in the city of Beirut. There are other workspaces in Lebanon that could be taken into consideration, but for administrative constraints, the researchers weren' $t$ able to access.

3) National researches about the quality of workspaces are few, therefore, there are lack of information and previous studies about this topic in Lebanon are rare.

The researchers would like to suggest the following recommendations:

1) The workspace has a very marked influence on individuals; therefore, it is essential to improve the quality of workspaces which leads to the enhancement of the quality of life of employees and their well-being.

2) Implementing greenery in workspaces (indoors and outdoors) due to its restorative impacts on productivity, health, and overall human behavior.

3) Investigating how the pandemic has redefined workspaces, and how we are going to adapt to the new approaches of design.

4) Increasing the common work between architects and psychologists is a must, in order to make better built environments and workspaces, in particular.

5) This research can form a standpoint for more national studies about the quality of workspaces.

6) The researchers expect that the present research contributes to the improvement of workspaces in Lebanon; they aspire to proceed and examine other variables such as quality of life, well-being, hardiness, cohesion and flourishing.

\section{References}

Abdel Kader, W.M. (2012). Architecture and Human Behavior: Does Design Affect Our Senses? Retrieved from www.scholar.cu.edu.eg

Abou Hamad, J. (2013), Using the Workspace as a Management Tool: A Conceptual Framework. Journal of Organizational Management Studies, (2013), Article ID 295350, 11 pages.

Akbari, P. \& Sattarisarbangholi, H. (2016). Architectural Design Based on Environmental Psychology Perspectives. The Turkish Online Journal of Design, Art and Communication - TOJDAC July 2016, Special Edition. Retrieved from http://www.tojdac.org/tojdac 
Asim, F. \& Shree, V. (2019). Biophilic Architecture for Restoration and Therapy within the Built Environment: A Review. Retrieved from https://www.researchgate.net/publication/334732892

Bukola, A., Peter, A., Omoyeni, F., Foluke, J., Albert, A. \& Oladunni, I., M. (2015). Designing to meet human needs: Place of environment-behaviour studies in architectural education, Global Journal on Humanities \& Social Sciences. Retrieved from http://www.world-education-center,org/index.php/ pntsbs

Bushiri, C.P. (2014).The Impact of Working Environment on Employees' Performance: The case of institute of Finance Management in Dar Es Salaam Region. Published Master Thesis in Human Resources Management. The Open University of Tanzania, Tanzania.

Carrer, P. \& Wolkoff, P. (2018). Assessment of Indoor Air Quality Problems in Office-Like Environments: Role of Occupational Health Services. International journal of Environmental Research and Public Health, 15(4), 741.

Cincinelli, A., \& Martellini, T. (2017). Indoor Air Quality and Health. International Journal of Environmental Research and Public Health, 14(11), 1286.

Elmahadi, M. A., Tahir, M. M., M. Surat, Tawil, N. M. \& I. M. S. Usman. (2011). Effective Office Environment Architecture: Finding Ingenious Ideas in a Home to Stimulate the Office Environment. The 2nd International Building Control Conference 2011. Procedia Engineering 20 (2011), 380-388.

Fox. , S. (2018, June 27). The importance of architectural design. Retrieved from www.foxdesignsny.com Janetius, S.T. (2016). Art, Culture \& Gender: The Indian Psyche. Mishil \& Js Publishers.

Kamarulzaman, N., Saleh, A.A., Hashim, S. Z., H. Hashim, H., Abdul-Ghani, A.A, (2011). An Overview of the Influence of Physical Office Environments towards Employees. The 2nd International Building Control Conference 2011. Procedia Engineering 20, 262 - 268.

Kopec, D., 2006. Environmental psychology for design. New York: Fairchild Publications.

Lottrup, L., Grahn, p. \& Stigsdotter, K.U. (2013). Workplace greenery and perceived level of stress: Benefits of access to a green outdoor environment at the workplace. Landscape and Urban Planning, 110(1), 511.DOI: 10.1016/j.landurbplan.2012.09.002

Namazian, A. \& Mehdipour, A. (2013). Psychological Demands of the Built Environment, Privacy, Personal Space and Territory in Architecture. International Journal of Psychology and Behavioral Sciences, 3(4), 109113.

O’Neil, M. (2008). Open Plan and Enclosed Private Offices: Research Review and Recommendations. Knoll Workplace Research. Retrieved from https://knoll.com/research/index.jsp

Pope, K. (12 June 2018). Why Designing Workspaces Should Be a Walk in the Park. Retrieved from www.blueprint.cbre.com

Robertson, C. (2015). Human Spaces: The Global Impact of Biophilic Design in the Workplace. HUMAN SPACES: The Global Impact of Biophilic Design in the Workplace. Retrieved from https://greenplantsforgreenbuildings.org

Rosli, N.F., \& Jalaluldin, J. (2012). Indoor Air Quality (IAQ) and sick Buildings Syndrome (SBS) among Office Workers in New and Old Buildings in Universiti Putra Malaysia, Serdang. Health and the Environment Journal, 3(2), 98-109.

Salah, A. (2010). The impact of workplace design on employees' performance: An Empirical study of the Administration Building of Islamic University of Gaza. Published Master Thesis. Islamic University of Gaza.

Savavibool, N., Gatersleben, B., \& Moorapun, C. (2018). The Effects of Colour in Work Environment: A systematic review. Asian Journal of Behavioural Studies, 3(13): 149-160.

Schaberl, R. (2019, June 30). The Green Workforce. Retrieved from https//www.bestworkspaces.com

Sonnentag, S. \& Frese, M. (2005). Performance Concepts and Performance Theory. Psychological Management of Individual Performance. Retrieved from https://www.researchgate.net/publication/291062476

Tomassoni, R., Galetta, G., \& Treglia, E. (2015). Psychology of Light: How Light Influences the Health and Psyche. Retrieved from http://www.scirp.org/journal/psych 
Tyrväinen, L., Ojala, A., Korpela, K., Lanki, T., Tsunetsugu, Y., \& Kagawa, T. (2014). The influence of urban green environments on stress relief measures: A field experiment. Journal of Environmental Psychology, (38): 1-9.

Vischer, J.C. (2008). Towards an Environmental Psychology of Workspace: How People are affected by Environments for Work. Architectural Science Review, 51(2): 97-108.

World Green Building Council, Health, Wellbeing \& Productivity in Offices. World Green Building Council, 2014. Retrieved from www.WGBC.org

What is the difference between a flexible workspace and a traditional office? Retrieved from

https://www.primeofficespace.co.uk/faq3.htm (Date of access: 7/11/2019).

https://dictionary.apa.org/environmental-psychology (Date of access: 1/11/2019).

https://www.antwork.com (Date of access: 20/11/ 2019).

https://www.togbeirut.com (Date of access: 20/11/ 2019).

https://www.slideshare.net/BorisZupani/workspace-the olive grove (Date of access: 5/1/2020). 